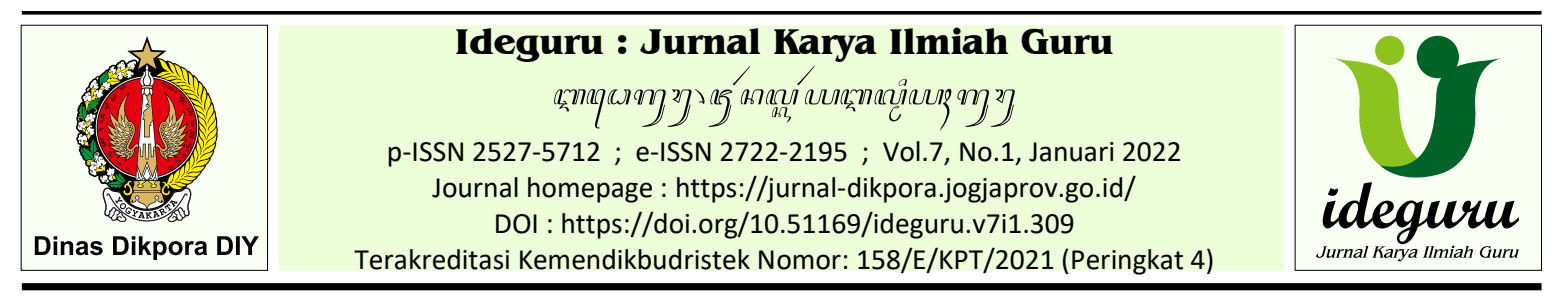

Best Practice - Naskah dikirim: 02/09/2021 - Selesai revisi: 10/10/2021 - Disetujui: 11/10/2021 - Diterbitkan: 01/01/2022

\title{
Layanan BAIIK sebagai Strategi BKK Guna Meningkatkan Keterserapan Alumni pada Dunia Kerja
}

\author{
Muis Lidinilah \\ SMK Negeri 2 Sukoharjo, Jawa Tengah, Indonesia \\ lidinilahmuis@gmail.com
}

\begin{abstract}
Abstrak: Salah satu ukuran keberhasilan Pendidikan Sekolah Menengah Kejuruan diantaranya dilihat dari tingginya angka penempatan di dunia kerja bagi tamatan sekolah tersebut. Namun saat ini berkembang isu di tengah masyarakat, bahwa SMK merupakan penyokong angka pengangguran terbesar di Indonesia. Beberapa permasalahan yang dihadapi calon tenaga kerja antara lain: kurangnya berlatih mengerjakan soal psikotest, kesulitan membuat berkas lamaran kerja, curriculum vitae, kurang percaya diri saat interview serta kegagalan saat medical ceck up,serta beberapa masalah di luar diri canaker. Hal tersebut mendorong penulis untuk bekerjasama dengan tim humas untuk bekerja keras membuat terobosan guna meningkatkan keterserapan kerja. Strategi Layanan BAIIK (Bimbingan Aktif Ikhlas Informatif Kooperatif) yang dilaksanakan penulis sejak tahun 2016 hingga sekarang ini bertujuan untuk meningkatkan keterserapan alumni di dunia kerja. Melalui strategi layanan ini keterserapan canaker pada dunia kerja di atas 80\% setiap tahunnya. Saran dari penulis kepada sekolah khususnya Waka Humas, supaya layanan ini dilakukan secara kontinyu, anggota tim humas ditambah dan mau bekerja secara pro aktif serta peduli kepada canaker. Selain itu canaker harus giat belajar, berlatih dalam berbagai hal guna meningkatkan kompetensinya supaya bisa bersaing dengan alumni sekolah lainnya.
\end{abstract}

Kata kunci: BAIIK (Bimbingan Aktif Ikhlas Informatif Kooperatif), Canaker, psikotes, curriculum vitae, interview, medical check up.

\section{BAIIK Services as a BKK Strategy to Increase Alumni Absorption in the Working World}

\begin{abstract}
One measure of the success of Vocational High School Education is seen from the high number of placements in the working world for school graduates. However, currently there is a growing issue in the community, that SMK is the biggest contributor to the unemployment rate in Indonesia. Some of the problems faced by job candidates include: lack of practice in doing psychological test questions, difficulty in making job application files, curriculum vitae, lack of confidence during interviews and failure during medical check-ups, as well as several problems outside of the job candidates. This encourages the author to work with the public relations team to work hard to make breakthroughs in order to increase work absorption. The BAIIK Service Strategy (Active Guidance Sincere Informative Cooperative) which has been implemented by the author since 2016 until now aims to increase the absorption of alumni in the working world. Suggestions from the author to schools, especially the Deputy Head of Public Relations, so that this service is carried out continuously, members of the public relations team are added and want to work proactively and care for job candidates. In addition, job candidates must study hard, practice in various ways in order to improve their competence so that they can compete with other school alumni.
\end{abstract}

Keywords: BAIIK (Active Guidance Sincere Informative Cooperative), Canaker, psychological test, curriculum vitae, interview, medical check up.

\section{Pendahuluan}

SMK/MAK merupakan bagian dari sistem pendidikan nasional yang memiliki tujuan pendidikan kejuruan yaitu menghasilkan tenaga kerja terampil yang memiliki kemampuan sesuai dengan tuntutan kebutuhan dunia usaha/ industri, serta mampu mengembangkan potensi dirinya dalam mengadopsi dan beradaptasi dengan perkembangan ilmu pengetahuan, teknologi, dan seni. (Permendikbud Nomor 34 Tahun 2018).

Tujuan khusus pendidikan SMK menurut Undang-Undang Nomor 20 Tahun 2003 adalah: (a) mempersiapkan peserta didik agar menjadi manusia produktif, mandiri, untuk dapat mengisi lowongan pekerjaan pada tingkat menengah sesuai dengan kompetensi dalam program keahliannya; 
(b) mempersiapkan peserta didik agar mampu berkarir, dan bersikap profesional dalam bidang keahliannya; (c) membekali peserta didik dengan ilmu pengetahuan, teknologi dan seni agar mampu berkembang menjadi manusia seutuhnya; dan (d) membekali peserta didik dengan keahlian dan ketrampilan yang sesuai dengan minatnya.

Namun saat ini berkembang isu di tengah masyarakat, bahwa angka pengangguran terbesar di Indonesia kebanyakan alumni dari SMK. Padahal lulusan SMK seharusnya sudah mempunyai ketrampilan, seperti ahli mesin mobil, sepeda motor, pengelasan, akuntansi, pertanian, peternakan, kelistrikan dan sebagainya.

Badan Pusat Statistik (BPS) dalam rilisnya pada akhir tahun 2020 kemarin mencatat bahwa Tingkat Pengangguran Terbuka (TPT) lulusan Sekolah Menengah Kejuruan masih menempati posisi tertinggi. TPT SMK tercatat pada angka $8,49 \%$. TPT adalah indikator pengukur ketidakterserapan manusia kerja di pasar kerja. TPT pada bulan Februari 2020 mencapai angka 4,99\%. Hal tersebut menunjukkan bahwa pada 100 orang angkatan kerja, terdapat sekitar 5 orang yang tidak bekerja (Victoria, 2020).

Faktor penyebab belum terserapnya pada dunia kerja lulusan SMK termasuk alumni SMK Negeri 2 Sukoharjo yang penulis amati beberapa tahun yang lalu, antara lain: (1) masih kurang berlatih dalam mengerjakan soal psikotest, kesulitan membuat berkas lamaran kerja, curriculum vitae, kurang percaya diri ketika interview serta kegagalan saat medical ceck up, (2) Struktur kurikulum SMK belum sesuai dengan kebutuhan dunia kerja di industri, (3) Jumlah lapangan kerja yang sedikit bagi alumni SMK dan sesuai dengan jurusannya, (4) kurangnya kerjasama sekolah dengan dunia usaha atau industri, dan sebagainya. Faktor faktor penyebab di atas menjadi tantangan tersendiri bagi penulis (ketua BKK) untuk mencari penyebabnya, dan solusi cara mengatasinya.

Tujuan dari pelaksanaan strategi layanan BKK ini adalah untuk meningkatkan keterserapan alumni pada dunia kerja di atas $80 \%$ setiap tahunnya. Permasalahan penting dan mendesak untuk dipecahkan pada best practice ini dirumuskan sebagai berikut: 1) bagaimana cara pemecahan masalah untuk mengatasi keterserapan alumni di dunia kerja?; 2) Apa strategi Bursa Kerja Khusus yang efektif untuk penempatan lulusan SMK?; 3) berapakah pencapaian Bursa Kerja Khusus pada pelaksanaan penempatan lulusan SMK?; 4) faktor apakah yang menjadi hambatan dan pendukung bagi keberhasilan program Bursa Kerja Khusus pada usaha penempatan lulusan SMK?

Pemecahan masalah dengan pendekatan layanan BAIIK (Bimbingan Aktif Ikhlas Informatif Kooperatif) merupakan solusi alternatif yang dilaksanakan oleh tim BKK guna meningkatkan keterserapan alumni SMK Negeri 2 Sukoharjo di dunia kerja. Inilah pengalaman terbaik yang dilakukan penulis sebagai ketua BKK SMK N 2 Sukoharjo.

Indikator keberhasilan dalam layanan BAIIK ini adalah alumni segera mendapat pekerjaan setelah lulus sekolah dengan masa tunggu kurang dari 3 bulan, dimana tingkat keterserapannya lebih dari $80 \%$. Keberhasilan lainnya adalah alumni yang bekerja sesuai dengan program keahliannya lebih dari 50\%.

\section{Tinjauan Pustaka}

Pengertian Bursa Kerja Khusus menurut (Pusdatinnaker, 2007) adalah "organisasi bursa kerja di Satuan Pendidikan Menengah, Pendidikan Tinggi dan Lembaga Pelatihan Kerja yang melakukan kegiatan pemberian informasi pasar kerja, pendaftaran pencari kerja, penyuluhan dan bimbingan karir serta penyaluran dan penempatan tenaga kerja. Pencari kerja adalah setiap orang yang mencari pekerjaan baik karena menganggur, putus hubungan kerja maupun orang yang sudah bekerja tetapi ingin mendapatkan pekerjaan yang sesuai dengan pendidikan, bakat, minat dan kemampuan yang dinyatakan melalui aktivitasnya mencari pekerjaan. Pemberi kerja adalah Instansi Pemerintah, Badan Usaha Milik Negara, Badan usaha Milik Swasta dan Perorangan yang membutuhkan tenaga kerja. Sementara itu istilah penyediaan tenaga kerja adalah suatu proses yang terdiri dari kegiatankegiatan pengumuman, penyuluhan, pendaftaran, interview dan seleksi para pencari kerja sesuai dengan persyaratan permintaan / kebutuhan tenaga kerja".

Menuurut Grant Venn dalam (London, 1973: 224) adalah penting sekali kegiatan penempatan lulusan dalam konsep bimbingan vokasional, di mana setiap institusi pendidikan harus mempunyai fungsi utama sebagai pembimbing dan konselor, serta penempatan dan tindak lanjutnya. Kepuasan dalam hal penempatan kerja adalah alasan utama mengapa orang memilih dan menyiapkan diri memasuki dunia kerja melalui sekolah kejuruan.

Konsep pekerjaan bagi masyarakat dapat dilihat dari berbagai sudut pandang, tetapi umumnya menyangkut pada dua hal, yaitu "bekerja sebagai upaya pemenuhan kebutuhan 
jasmani: sandang, pangan, papan, serta kebutuhan rohani, pemenuhan kepuasan mental spiritual serta bernilai ibadah" (Tohari Musnamar, 1992: 120).

Kesempatan bagi peserta didik untuk memahami dunia kerja dengan segala seluk beluknya sangat terbatas, sehingga mereka memerlukan bimbingan dan informasi. Sedangkan salah satu ukuran keberhasilan Pendidikan Sekolah Menengah Kejuruan diantaranya dilihat dari tingginya angka penempatan di dunia kerja bagi alumni sekolah tersebut (Sabri, 2021). Sementara bagi masyarakat, alumni SMK diharapkan menjadi sumber daya dan tenaga bagi roda perekonomian mereka. Jika mereka tidak bekerja maka akan membebani keluarga atau masyarakat, sedangkan apabila mereka bekerja maka masyarakat akan terbantu sosial ekonominya.

Menurut Smith dkk (dalam Prayitno 1999: 94), "bimbingan adalah proses layanan yang diberikan kepada individu guna membantu mereka memperoleh pengetahuan dan keterampilan yang diperlukan dalam membuat pilihan, rencana dan interpretasi yang diperlukan untuk menyesuaikan diri dengan baik".

Sementara itu bimbingan menurut Prayitno dan Erman Amti (Prayitno, 2004), adalah "proses pemberian bantuan yang dilakukan oleh orang yang ahli kepada seseorang atau beberapa orang individu, baik anak-anak, remaja, maupun dewasa, agar orang yang dibimbing dapat mengembangkan kemampuan dirinya sendiri dan mandiri, dengan memanfaatkan kekuatan individu dan sarana yang ada dan dapat dikembangkan berdasarkan norma-norma yang berlaku".

Oleh karena itu dapat dirumuskan bahwa, Bimbingan dan Konseling (BK) merupakan serangkaian kegiatan pemberian bantuan konseling yang dilakukan oleh seorang ahli dengan cara tatap muka, baik secara individu atau kelompok guna mengatasi permalahan yang dialami oleh konseli, secara cara terus menerus dan terstruktur.

Pengertian kata Aktif menurut Kamus Besar Bahasa Indonesia (KBBI Online, 2021) berarti giat. Kegiatan peserta didik pada saat proses pembelajaran perlu diperhatikan oleh guru, supaya proses belajar mengajar mendapatkan hasil yang maksimal.

Pengertian ikhlas menurut Kamus Besar Bahasa Indonesia adalah "bersih hati atau tulus hati". Dalam agama Islam, ikhlas merupakan cara manusia untuk mendapatkan ketenangan jiwa. Hanya orang beriman kuat yang bisa berlaku ikhlas, karena itu sikap ini sangat mulia dan terpuji. Niat ikhlas memanglah harus dilandasi oleh kesucian hati semata-mata hanya ingin tolong menolong dan mengharap pahala dari Allah bukan mengharap pujian dari orang banyak.

Makna informatif pada (KBBI, 2021) adalah: "bersifat memberi informasi; bersifat menerangkan". "Informasi yang dimaksud di sini adalah informasi yang memiliki kaitan bersama aktivitas dengan berbagai pihak. Contohnya, seorang sales yang ingin meningkatkan target pencapaiannya, maka ia akan berusaha untuk memasang iklan di berbagai media" (Niko Ramadhani, 2020).

Jadi informatif adalah segala sesuatu yang bersifat memberi informasi atau menerangkan. Apapun bentuk medianya, jika dapat memberikan informasi dan menerangkan sesuatu sehingga penerima memahami apa yang disampaikan maka media itu dikatakan informatif.

\section{Pembahasan \\ Metode Pelaksanaan Layanan BAIIK}

Agar diperoleh hasil yang maksimal sesuai dengan tujuan yang ingin dicapai, maka Bursa Kerja Khusus SMK Negeri 2 SUKOHARJO sejak 5 tahun terakhir ini (2016-sekarang) telah menjalankan strategi yang baik dan cukup berhasil dalam menaikkan keterserapan alumninya di berbagai bidang pekerjaan. Strategi ini dinamai layanan BAIIK, yaitu akronim dari: Bimbingan Aktif Ikhlas Informatif Kooperatif.

Jadi layanan BAIIK adalah sebuah layanan yang dilakukan penulis sebagai petugas BKK SMK Negeri 2 Sukoharjo guna meningkatkan keterserapan alumni SMK Negeri 2 Sukoharjo di dunia kerja.

Adapun proses pelaksanaan layanan BAIIK ini dijelaskan secara rinci di bawah ini:

\section{Bimbingan dan Konseling}

Sesuai pengertian bimbingan dan konseling di atas, maka BKK SMK N 2 Sukoharjo senantiasa menjalankan program bimbingan ini kepada para para peserta didik kelas 12 maupun alumni.

Bimbingan dan penyuluhan yang dilakukan dalam layanan ini adalah sebagai berikut: (1) melaksanakan simulasi pengerjaan soal TPA/ Psikotes, bagaimana cara membuat surat lamaran kerja, curriculum vitae, dan sebagainya. (2) memberikan support, motivasi dan bimbingan dalam menghadapi psikotes, interview, MCU dan seterusnya. (3) memberikan layanan dalam menghadapi persoalan administrasi dengan perusahaan tempat kerja. (4) layanan bimbingan ini juga disampaikan dalam group WA 
kelas/chatting WA, group lowker maupun komen lewat group BKK di Facebook di luar jam dinas. (5) Bimbingan kadang dilakukan di ruang BKK kepada peserta didik yang datang secara pribadi, maupun pengurus kelas mewakili anggotanya di ruang BKK. Kegiatan kegiatan di atas dilakukan pada saat peserta didik di kelas/workshop/lab dengan meminta izin pada guru / instruktur terutama pada saat pelajaran produktif. Gambar 1 ini menunjukkan saat penulis memberikan bimbingan pembuatan lamaran, curriculum vitae pada calon tenaga kerja.

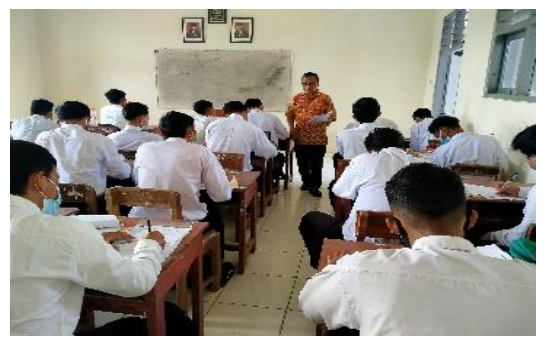

Gambar 1. Memberi bimbingan tentang format lamaran, pengarahan sebelum interview.

Aktif / Giat (Bekerja, Berusaha)

Pelaksanaan kegiatan aktif dalam layanan BKK ini antara lain: 1) keaktifan BKK dalam mendapatkan informasi lowongan kerja, baik melalui media online, informasi antar BKK, penelusuran informasi ke HRD perusahaan, alumni dan sebagainya. 2) keaktifan dalam mengikuti BIMTEK BKK yang diadakan oleh Disnaker Propinsi Jawa Tengah, guna memperoleh wawasan, strategi, layanan BKK online dan sebagainya. 3) keaktifan peserta didik/alumni dalam mencari dan membutuhkan bantuan, bimbingan maupun layanan lainnya. 4) keaktifan penulis dalam mendampingi calon tenaga kerja saat seleksi psikotes dan sebagainya.

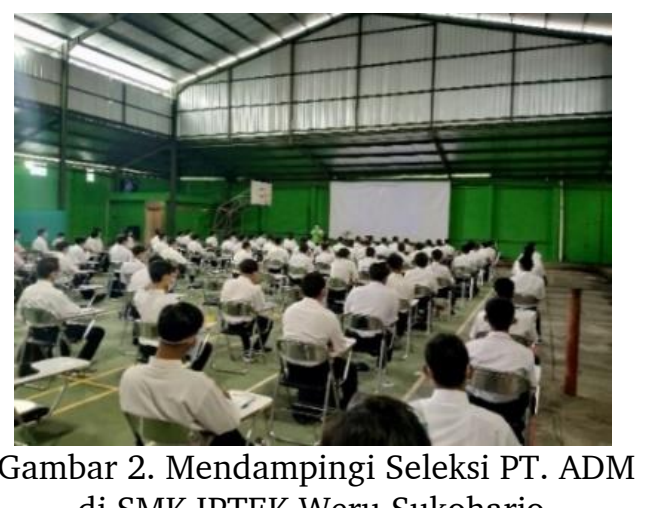

di SMK IPTEK Weru Sukoharjo.

Seperti yang ditunjukkan dalam gambar 2, penulis mendampingi saat seleksi PT.HPM di SMK GANESHA TAMA Boyolali. Hal ini bertujuan untuk memberikan dukungan moril bagi peserta, membantu mereka menyiapkan diri sebelum tes, serta untuk menjalin kerjasama/ silaturahmi dengan team seleksi maupun pengurus BKK lainnya.

Hasil keaktifan penulis dalam mengikuti berbagai kegiatan Bintek, workshop, penyuluhan dari Disnaker, Dinas Pendidikan berbagai pihak ini, bisa dilihat dalam tabel 1 di bawah. Pada tabel tersebut disebutkan beberapa kegiatan, waktu, tempat pelaksanaan serta penyelenggara kegiatan. Semua kegiatan dalam tabel 1 tersebut bertujuan untuk memandu jalannya BKK supaya sesuai dengan koridor, peraturan pemerintah.

Tabel 1. Daftar Kegiatan Bintek yang diikuti

\begin{tabular}{|c|c|c|c|c|}
\hline No & Kegiatan & $\begin{array}{c}\text { Waktu } \\
\text { Pelaksanaan }\end{array}$ & Tempat Pelaksanaan & Penyelenggara \\
\hline 1 & $\begin{array}{l}\text { Penyuluhan Informasi } \\
\text { Pasar Kerja Angkatan } 1\end{array}$ & 19 Agustus 2015 & $\begin{array}{l}\text { Syariah Hotel Solo Jl. Adi } \\
\text { Sucipto } 47 \text { Colomadu } \\
\text { Karanganyar }\end{array}$ & $\begin{array}{l}\text { Kementrian } \\
\text { Ketenagakerjaan } \\
\text { Republik Indonesia }\end{array}$ \\
\hline 2 & $\begin{array}{l}\text { Seminar Nasional: Peran } \\
\text { Pendidikan Vokasi dalam } \\
\text { Menyongsong MEA } 2016\end{array}$ & $\begin{array}{l}15 \text { September } \\
2016\end{array}$ & $\begin{array}{l}\text { Aula Cabdin.Wilayah VII } \\
\text { Jl. Slamet Riyadi } 1 \\
\text { Kauman Surakarta }\end{array}$ & $\begin{array}{l}\text { Dinas Pendidikan } \\
\text { Propinsi Jawa Tengah }\end{array}$ \\
\hline 3 & $\begin{array}{l}\text { Bimbingan Teknis } \\
\text { Peningkatan Kapasitas } \\
\text { Layanan } \\
\text { Bursa Kerja Khusus (BKK) } \\
\text { Di SMK Tahap IV }\end{array}$ & $\begin{array}{l}\text { 11-13 September } \\
2017\end{array}$ & $\begin{array}{l}\text { Di Grand Keisha Yogyakarta } \\
\text { Jln. Affandi } 9 \text { Caturtunggal } \\
\text { Depok Sleman Yogyakarta. }\end{array}$ & $\begin{array}{l}\text { DirJen. Pendidikan } \\
\text { Dasar dan Menengah } \\
\text { Kementerian Pendidikan } \\
\text { Dan Kebudayaan } \\
\text { Republik Indonesia }\end{array}$ \\
\hline 4 & $\begin{array}{l}\text { Bintek Penyelenggaraan } \\
\text { layanan BKK di SMK }\end{array}$ & $\begin{array}{l}\text { 03-05 September } \\
2018\end{array}$ & $\begin{array}{l}\text { Di Hotel Brothers Jl. Raya } \\
\text { Solo Baru }\end{array}$ & Disnaker Jawa Tengah \\
\hline 5 & $\begin{array}{l}\text { Bintek Pengelola BKK } \\
\text { SMK }\end{array}$ & 24-26 Juli 2019 & $\begin{array}{l}\text { Di Alana Hotel Jl. Adi } \\
\text { Sucipto, Blulukan } \\
\text { Colomadu Karanganyar }\end{array}$ & Disnaker Jawa Tengah \\
\hline 6 & Bintek Pembinaan BKK & $\begin{array}{l}\text { 18-20 Nopember } \\
2019\end{array}$ & $\begin{array}{l}\text { Di Hotel Best western Jl. } \\
\text { Raya Solo Baru }\end{array}$ & Disnaker Jawa Tengah \\
\hline
\end{tabular}




\section{Ikhlas}

Keikhlasan ini yang menjadi salah satu perilaku BKK selama ini. Diantara bentuk layanan ini adalah: 1) Ikhlas dan siap memberikan layanan,menjawab pertanyaan kepada siapa saja, baik kepada peserta didik kelas 12, alumni SMK Negeri 2 Sukoharjo,maupun alumni dari SMK lain yang membutuhkan informasi, penjelasan, pendaftaran pekerjaan dalam 24 jam. 2) Kesiapan dalam pembuatan dokumen yang diperlukan Canaker, baik itu surat ijin orang tua,surat permohonan NPWP, dan administrasi lainnya yang diperlukan Canaker, 3) Siap mendampingi saat seleksi maupun berangkat kerja dan sebagainya walaupun tanpa biaya perjalanan dari sekolah.

Gambar 3 adalah salah satu bentuk layanan ikhlas dalam menjawab komunikasi dari para calon tenaga kerja di luar jam dinas. Seringkali terjadi bila besuk pagi diselenggarakan seleksi,maka hampir dipastikan banyak chatting masuk pada HP di malam hari. Maka sebagai pengelola BKK harus senantiasa sabar, ikhlas dalam melayani Canaker dalam menjawab berbagai pertanyaan, walaupun itu pertanyaan sepele.

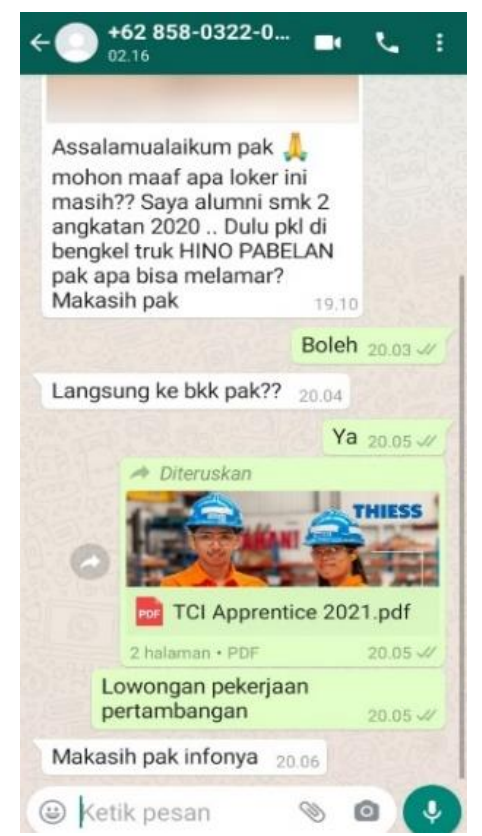

Gambar 3. Layanan WA di luar jam dinas.

Pada gambar 4, menunjukkan salah satu bentuk keikhlasan dalam layanan BKK, yaitu menguji/memeriksa fisik calon karyawan PT. Astra Daihatsu Motor. Padahal tes fisik ini seharusnya dilakukan oleh pihak HRD.Namun supaya terjadi efisiensi waktu, tenaga dan sebagainya, maka tes fisik dipersilahkan dilakukan oleh pihak BKK.

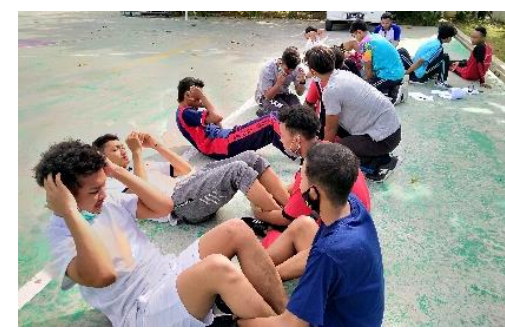

Gambar 4. Menguji tes fisik PT. ADM.

Informatif (Bersifat Memberi Informasi;

Bersifat Menerangkan)

Diantara bentuk layanan BKK berikutnya adalah senantiasa memberikan informasi yang terbuka kepada masyarakat sekolah maupun masyarakat umum lainnya.

Pelaksanaan informatif dalam layanan BKK ini adalah: (1) Pada awalnya kita menyampaikan informasi lewat lisan dari kelas ke kelas, namun itu membutuhkan banyak waktu dan tenaga. (2) Penyampaian informasi melalui media facebook. Grup dengan nama BKK SMK N 2 SUKOHARJO P.MUIS LIDINILAH ini dibuat pada 13 November 2012, saat ini memiliki anggota lebih dari 35.700 orang, dan ada lebih dari 1000 -an permintaan anggota yang belum kita respon. Penggunaan media facebook saat ini banyak menjangkau lapisan masyarakat di seluruh dunia. Segala hal bisa kita sampaikan di media sosial ini, baik informasi lowongan kerja, hasil seleksi, tahapan lanjut seleksi dan informasi diterima / tidaknya seorang calon tenaga dalam sebuah seleksi. (3) Pada saat ini penyampaian informasi bisa lewat WA group, Instagram dan sebagainya, dibantu dengan berbagai aplikasi di office 365 membuat pendaftaran canaker lebih cepat dan mudah.

Implementasi layanan informatif salah satunya ditunjukkan pada gambar 5 di bawah ini. Informasi yang disampaikan baik lewat goup Facebook, Instagram, WhatssApp antara lain, aktif menyebarkan informasi yang berkaitan dengan lowongan kerja, jadwal seleksi, hasil seleksi dan sebagainya.

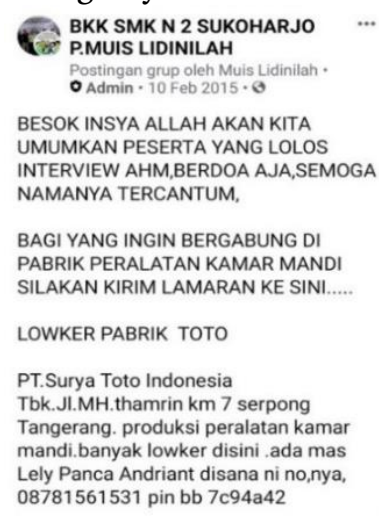

Gambar 5. Poster informasi kerja di group Facebook. 
Kooperatif (Banyak Membangun Kerja Sama) Makna kooperatif dalam Kamus Besar Bahasa Indonesia (KBBI Online, 2021), adalah bersifat kerja sama, bersedia membantu/ menolong. Bentuk strategi layanan kooperatif adalah: 1) BKK SMK Negeri 2 Sukoharjo senantiasa menjalin kerja sama dengan berbagai pihak demi terserapnya alumni pada dunia kerja. 2) Kerja sama ini bisa terjadi antara BKK SMK Negeri 2 Sukoharjo dengan berbagai perusahaan /industri/pemberi kerja lainnya. 3). Selain itu kegiatan kerja sama bisa dilakukan dengan berbagai BKK mitra yang juga menyalurkan calon tenaga kerja yang dituangkan dalam bentuk MoU.

Tabel 2 ini adalah berisi daftar MoU yang dilakukan pihak BKK dengan berbagai industri maupun BKK mitra guna tukar informasi, penyaluran tenaga kerja, penyaluran peserta didik yang akan melaksanakan prakerin, magang guru dan sebagainya.

Tabel 2. Daftar Kerja Sama antara DUDI, BKK MITRA dengan BKK SMK N 2 Sukoharjo

\begin{tabular}{|c|c|c|c|}
\hline No & Nama Iduka & Alamat & Keterangan \\
\hline 1 & $\begin{array}{l}\text { PT. Nasmoco Bengawan } \\
\text { Motor }\end{array}$ & $\begin{array}{l}\text { J1. Slamet Riyadi No. 558, Solo } \\
\text { Surakarta, Jawa Tengah, Indonesia } \\
\text { 57144. Phone: (0271) 715355. Fax: } \\
\text { 0271-711185. }\end{array}$ & $\begin{array}{l}\text { Dealer, Spare part } \\
\text { dan layanan purna } \\
\text { jual }\end{array}$ \\
\hline 2 & Roti Ganep Solo & $\begin{array}{l}\text { Jl. Sutan Syahrir No.176, Setabelan, } \\
\text { Kec. Banjarsari, Kota Surakarta, } \\
\text { Jawa Tengah } 57133\end{array}$ & Roti, dan Cateering \\
\hline \multirow[t]{2}{*}{3} & PT. Japan Indonesian & Jl. Ir. H. Juanda, Kav Adhikarya No & Penempatan magang \\
\hline & $\begin{array}{l}\text { Economic Center (PT. } \\
\text { JIAEC) }\end{array}$ & $\begin{array}{l}\text { 20, Kal. Bakti Jaya, Kec. Sukmajaya, } \\
\text { Depok. }\end{array}$ & Jepang \\
\hline \multirow[t]{2}{*}{4} & PT. Minori & $\begin{array}{l}\text { Jl. Raya Cibarusah No } 21 \mathrm{~J}, \\
\text { Cikarang }\end{array}$ & $\begin{array}{l}\text { Penempatan magang } \\
\text { Jepang }\end{array}$ \\
\hline & & $\begin{array}{l}\text { Cibarusah 17550, Bekasi. } \\
\text { (021)8974-540, (021)22104372 }\end{array}$ & \\
\hline \multirow[t]{2}{*}{5} & PT. PAMA PERSADA & Jl. Rawagelam 1 No.9, Jakarta & Kontraktor \\
\hline & & $\begin{array}{l}\text { Industrial Estate Pulo Gadung, } \\
\text { Jakarta } 13930 \text { (021) } 4602015 \text { - } \\
4610624\end{array}$ & $\begin{array}{l}\text { Pertambangan } \\
\text { batubara }\end{array}$ \\
\hline 6 & PT. Indomarco (Indomart) & Delanggu klaten & $\begin{array}{l}\text { Retail kebutuhan } \\
\text { rumah tangga }\end{array}$ \\
\hline 7 & PT. Super Unggas Jaya & Polokarto Sukoharjo & Penetasan telur ayam \\
\hline 8 & PT. Sritex Sukoharjo & KH. Saman Hudi 88 Jetis Sukoharjo & $\begin{array}{l}\text { Pemintalan, tenun, } \\
\text { kain, Garmen }\end{array}$ \\
\hline 9 & PT. Karyatama & Ruko Bulakrejo Sukoharjo & $\begin{array}{l}\text { Penempatan tenaga } \\
\text { kerja Malaysia }\end{array}$ \\
\hline 10 & $\begin{array}{l}\text { PT. Sinar Agung Selalu } \\
\text { Sukses }\end{array}$ & $\begin{array}{l}\text { Ngalasan RT.02/RW.01 Brujul, } \\
\text { Jaten, Karanganyar, Jawa Tengah, } \\
\text { Indonesia }\end{array}$ & $\begin{array}{l}\text { Pembuatan spart part } \\
\text { otomotif baik logam, } \\
\text { plastik, karet dsb. }\end{array}$ \\
\hline 11 & Soto Sedaap Boyolali $\mathrm{Hj}$ & Pusat di Colomadu Karanganyar & Sebuah Perusahaan \\
\hline & Widodo & & $\begin{array}{l}\text { Kuliner dengan Visi } \\
\text { Mendunia. }\end{array}$ \\
\hline 12 & $\begin{array}{l}\text { PT. Rayon Utama Makmur } \\
\text { Sukoharjo }\end{array}$ & Desa Plesan, Nguter, Sukoharjo & produksi serat rayon \\
\hline 13 & SMK N 2 Surakarta & JL. Adi Sucipto Surakarta & BKK AFILIASI \\
\hline 14 & SMK N 2 Salatiga & $\begin{array}{l}\text { Jl. Parikesit, Dusun Warak, Desa } \\
\text { Dukuh, Kecamatan Sidomukti, Kota } \\
\text { Salatiga. }\end{array}$ & BKK AFILIASI \\
\hline 15 & SMK N 2 Depok Sleman & $\begin{array}{l}\text { Jl. STM Pembangunan, Mrican, } \\
\text { Caturtunggal, Depok, Sleman, DIY }\end{array}$ & BKK AFILIASI \\
\hline
\end{tabular}


Selain itu kegiatan kunjungan kerjasama, job matching, pemasaran tamatan sering kita lakukan, seperti yang ditampilkan dalam gambar 6.

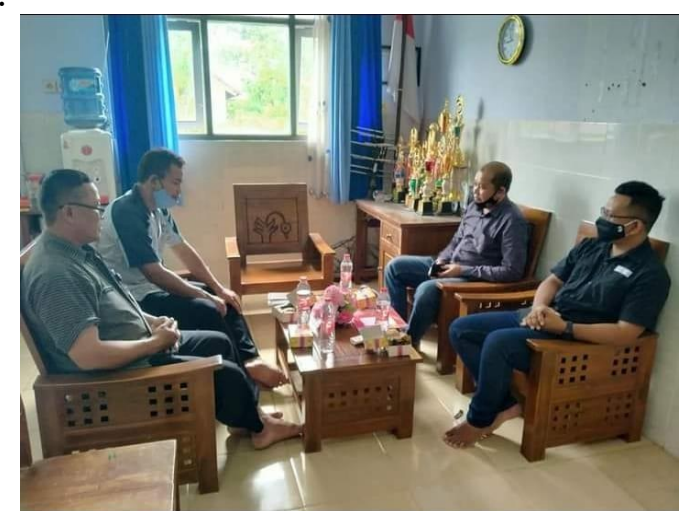

Gambar 6. Kunjungan PT. Guna Jaya (ternak) Dalam tukar rangka informasi kerja.

\section{Hasil/ Manfaat, Kendala serta Faktor Pendukung Program}

Pelaksanaan Layanan BAIIK merupakan pengalaman terbaik BKK SMK Negeri 2 Sukoharjo sejak tahun 2015. Layanan ini sangat besar pengaruh dan manfaatnya baik bagi penulis, peserta didik / alumni, maupun pihak sekolah. Manfaat layanan BAIIK diuraikan sebagai berikut:

Penulis merasakan bahwa tugas sebagai pengelola BKK merupakan sebuah ladang amal selain tugas pokok sebagai guru produktif otomotif, karena prinsip penulis adalah seperti tertulis dalam Al-qur'an Surat Al Muddatstsir ayat 42-44,

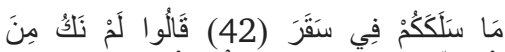

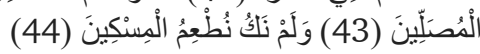

"Penduduk surga bertanya kepada penduduk neraka) apa yang menyebabkan kalian masuk ke neraka (Saqor)? Mereka (penduduk neraka) berkata: Kami dulu bukan termasuk orang-orang yang shalat. Kami pun tidak memberi makan kepada orang-orang miskin". (Q.S al-Muddatstsir ayat 42-44).

Agama Islam bukan hanya ajaran individualis, tetapi ajaran yang mengedepankan distribusi kebaikan kepada orang banyak. Itulah salah satu keindahan dan keagungan agama Islam.

Penulis juga dapat membuat karya ilmiah yang dapat dimanfaatkan oleh masyarakat sekolah maupun kegiatan ilmiah lainnya. Dengan budaya menulis ini diharapkan dapat meningkatkan kualitas pendidik, juga untuk menambah Penialain Angka Kredit bagi penulis.

Manfaat bagi canaker adalah mereka bersemangat dalam mengikuti berbagai kegiatan layanan BKK. Kenyataanya ketika memperoleh informasi lowongan kerja, mereka bersemangat untuk mendaftar dan lebih mempersiapkan diri supaya lolos di dunia kerja. Kalaupun mereka tidak diterima di salah satu perusahaan, mereka tidak mudah putus asa, karena masih banyak dunia kerja yang membutuhkan calon karyawan. Selain itu mereka pun masih bisa usaha mandiri aataupun berwirausaha di sekitar tempat tinggalnya. Hasil penelusuran tamatan yang disebar tiap tahun menunjukkan bahwa jumlah keterserapan alumni di dunia kerja senantiasa meningkat di atas $80 \%$. Hasil dari keterserapan kerja 4 tahun terakhir ini dapat dilihat pada diagram 1.

\section{Keterserapan Alumni SMK N 2 SKH Tahun 2016-2019}

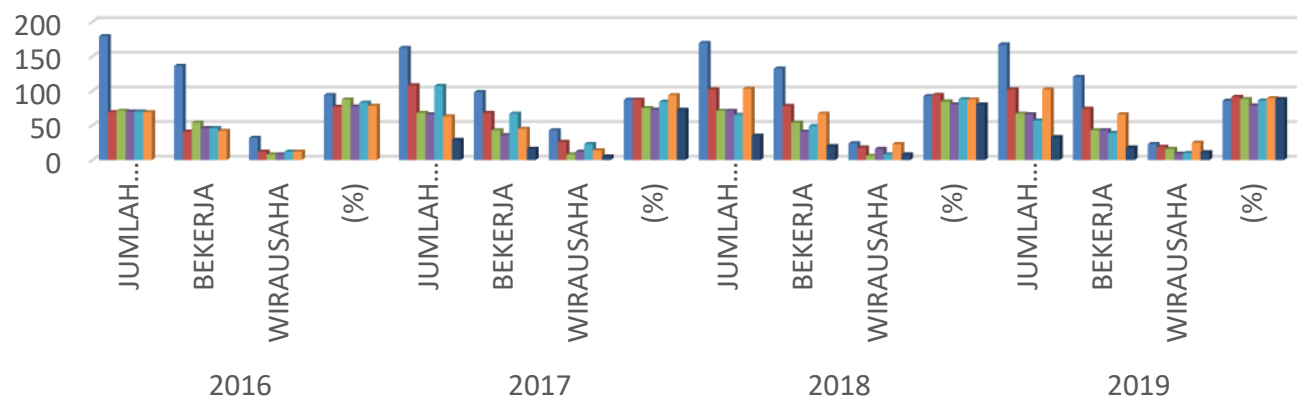

$$
\begin{aligned}
& \text { — } 1 \text { TEKNIK KENDARAAN RINGAN } \\
& \text { — } 3 \text { TEKNIK MEKATRONIKA } \\
& 5 \text { AGRIBISNIS TERNAK RUMINANSIA } \\
& \text { — } 2 \text { TEKNIK MEKANIK INDUSTRI } \\
& 4 \text { TEKNIK GAMBAR BANGUNAN } \\
& 6 \text { TEKNIK KIMIA INDUSTRI }
\end{aligned}
$$

Diagram 1. Gambar keterserapan alumni SMK N 2 Sukoharjo di dunia kerja. 
Pada diagram 1 di atas menunujukkan bahwa terdapat peningkatan jumlah keterserapan alumni di dunia kerja, terutama jurusan teknik, sebagian besar diterima kerja di sektor industri (PT. ADM, PT. AHM, PT. SHOWA, PT. AISIN, PT. KAYABA, PT. SRITEX dan sebagainya). Pengambilan data melalui penyebaran angket yang dilakukan pihak BKK ke tamatan setiap tahunnya. Namun demikian terdapat juga alumni yang bekerja di bidang wirausaha di daerah sekitar maupun ikut merantau dengan saudaranya di luar daerah.

Gambar 7 menunjukkan persiapan keberangkatan kerja alumni di sebuah perusahaan pengolahan kelapa sawit, yakni PT.BGA Sampit Kalimantan Tengah.

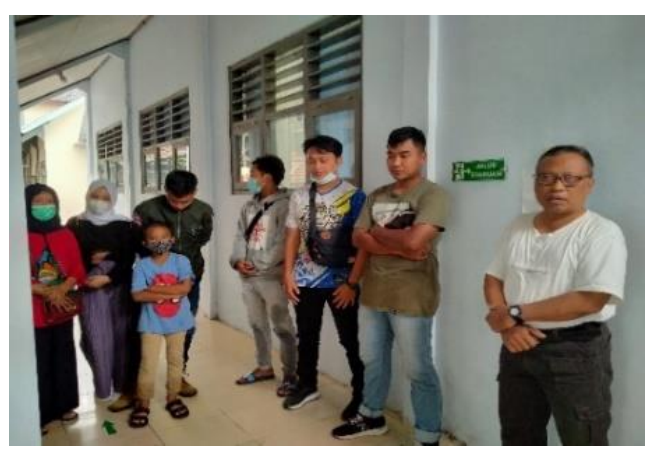

Gambar 7. Pemberangkatan ke PT. BGA, Kalimantan Tengah.

\section{Bagi pihak sekolah}

Manfaat layanan BKK bagi sekolah anatara

lain: 1) Melaksanakan kewajiban undang undang, sehingga tujuan pendidikan SMK tercapai.2) Meningkatkan hubungan sekolah dengan industri dan masyarakat. 3) Meningkatkan nama baik sekolah di mata masyarakat sehingga setiap penerimaan peserta didik baru senantiasa diminati oleh masyarakat. 4) Menyediakan tenaga kerja bagi perusahaan. 5) Dapat menyesuaikan kurikulum pendidikan sesuai dengan kebutuhan lapangan kerja.

\section{Kendala dan Faktor Pendukung}

Beberapa kendala yang dihadapi Bursa Kerja Khusus SMK N 2 Sukoharjo dalam menjalankan strategi layanan BAIIK adalah sebagai berikut: (1) Kendala manajemen, antara lain: jumlah personel BKK yang minim, dan tidak setiap orang guru mau berkurban waktu dan tenaga. (2) Tidak adanya dana operasional guna membantu kelancaran BKK. Penggunaan biaya yang cukup besar adalah untuk komunikasi dan pemasaran tamatan (job Matching) lulusan ke perusahaan, dan seterusnya. (3) Kendala budaya. Maksudnya adalah masih kuatnya budaya malu untuk maju dari para calon alumni. Juga slogan Mangan ora Mangan Seng Penting Kumpul (hanya mau bekerja di daerah asal). (4) Kendala fisik yang dimiliki peserta didik. Maksudnya, sebagian besar anak anak yang cerdas, baik attitutednya, namun memiliki tinggi fisik yang kurang dari stradar perusahaan (misalnya tinggi laki laki $\min .163 \mathrm{~cm}$, wanita $158 \mathrm{~cm}$ ). Selain itu kendala umur, dimana saat mendaftar pekerjaan sebagian peserta didik masih berusia kurang dari 18 tahun. (5) Sikap apatis dari lulusan. Mereka tidak melaporkan diri sebagai pencari kerja maupun setelah mendapatkan pekerjaan, lulusan masih pilih-pilih pekerjaan, dan sebagainya. (6) Kendala pada penulis, dimana penulis selain memiliki beban mengajar minimal 24 jam, juga diamanahi sebagai ketua BKK dan wali kelas. Apalagi jam kerja menjadi 5 hari kerja, sehingga pelayanan bimbingan ke tiap kelas 12 hanya bisa dilakukan kurang dari 3 kali setahun.

Pada pelaksanaan layanan BAIIK BKK SMK $\mathrm{N} 2$ Sukoharjo ini ada beberapa faktor pendukung, diantaranya adalah: (1) peserta didik/alumni memiliki kemauan yang tinggi dalam mengikuti bimbingan dan penyuluhan, karena mereka merasa sangat membutuhkan. (2) layanan BAIIK ini terbukti mampu memotivasi peserta didik dalam mendaftar berbagai macam perusahaan bila ada seleksi, walaupun seringkali pelaksanaan seleksi di luar daerah Sukoharjo. (3) dukungan dari para guru kelas, wali kelas terhadap pelaksanaan layanan BAIIK ini, karena mereka juga merasa bangga bila peserta didiknya segera mendapatkan pekerjaan walaupun belum lulus sekolah. (4) sekolah mendukung strategi layanan BKK ini dengan memberikan support dan ruang gerak untuk berkembang lebih baik.

\section{Simpulan dan Saran}

Pelaksanaan layanan BAIIK (Bimbingan Aktif Ikhlas Informatif dan Kooperatif) BKK SMK $\mathrm{N} 2$ Sukoharjo dapat memberikan motivasi kepada peserta didik untuk lebih semangat dalam belajar, karena mereka termotivasi untuk segera dapat pekerjaan sesudah lulus sekolah. Layanan BKK ini dapat pula meningkatkan jumlah alumni yang diterima kerja lebih dari $80 \%$ pada beberapa tahun terakhir ini. Dengan meningkatnya alumni yang diterima kerja, menjadikan rujukan bagi masyarakat untuk menyekolahkan putra putrinya di SMK N 2 Sukoharjo.

Kendala-kendala yang dihadapi BKK dalam pelaksanaan layanan ini antara lain; berupa hambatan manajerial seperti kurangnya pendanaan, kurangnya personel BKK, kendala usia dan kondisi fisik canaker. Kendala lain berupa hambatan budaya, alumni tidak melapor setelah mendapatkan pekerjaan, alumni enggan 
untuk bekerja di luar daerah, alumni terlalu selektif dalam memilih pekerjaan, kurang percaya diri bekerja sesuai bidang keahliannya, serta kurangnya lapangan kerja.

Berdasarkan kesimpulan dalam pengalaman terbaik guru ini, penulis memberi masukan sebagai berikut, (1) Kegiatan layanan BKK perlu dilakukan secara intensif dan terus menerus. Hal ini dapat berlangsung dengan baik bila sekolah senantiasa memfasilitasi kegiatan BKK. Misalnya dengan tambahan tenaga yang cakap dalam teknologi informasi dan energik, adanya anggaran operasional yang bisa digunakan untuk mendukung kegiatan BKK, pengakuan jam mengajar bagi pengurus BKK / pengurangan tugas tambahan petugas BKK. (2) Para guru diharap lebih peduli terhadap anak didiknya dalam mengembangkan karier mereka. Tugas guru selain sebagai pendidik, juga sebagai pembimbing masa depan anak didiknya. Sehingga mereka cepat dapat beradaptasi dengan dunia kerja. 3) Adanya guru BKK yang berjiwa sosial tinggi, siap bekerja tanpa mengenal waktu dan tenaga 4) Canaker hendaknya lebih giat dalam belajar dan berlatih baik saat masih sekolah, maupun setelah lulus. Sehingga ketika ada lowongan kerja mereka memiliki kesiapan. Selain itu jangan terlalu selektif dalam mencari pekerjaan, karena beberapa lowongan pekerjaan yang berupa mekanik/maintenance peminatnya sedikit dibanding dengan operator.

\section{Daftar Pustaka}

(2021). Kamus Besar Bahasa Indonesia 2012-2021 versi 2.8 . https://kbbi.web.id/aktif.

London, H H. (1973). Principles and Techniques of Vocational Guidance. Columbus: Charles E Merril Publishing Co.
Sabri, B., \& Mulyadi, E. (2021). Implementation of the "Pair System\&quot; Strategy to Increase Validity of Graduates Tracking. Ideguru: Jurnal Karya Ilmiah Guru, 6(1), 27-34. https://doi.org/10.51169/ideguru.v6i1.189

Prayitno. (1999). Pelayanan Bimbingan dan Konseling Sekolah Menengah Umum (SMU). Padang: Penebar Aksara.

Prayitno dan Erman Amti. (2004). Dasar-dasar Bimbingan dan Konseling. Jakarta: Rineka Cipta.

Pusat Data dan Informasi Ketenagakerjaan. (2007). Istilah dalam Bursa Kerja. Glosarium Ketenagakerjaan.

Pendidikan Menengah Kejuruan. (1995). Pedoman Bimbingan dan Penyuluhan Kejuruan, Jakarta: Depdikbud.

Permendikbud Nomor 34 Tahun 2018. Tentang Standar Nasional Pendidikan Sekolah Menengah Kejuruan/Madrasah Aliyah Kejuruan, Jakarta.

Ramadhani, Niko. (2020). "Unsur, Fungsi dan Tujuan dalam Komunikasi Bisnis" https://www.akseleran.co.id/blog/komunik asi-bisnis/ diambil 25/06/2020.

Tohari Musnamar dkk (1992). Dasar-dasar Konseptual Bimbingan Konseling Islami. Yogyakarta: UII Press.

Undang-Undang Republik Indonesia No.20 Tahun 2003 Tentang Sistem Pendidikan Nasional. Jakarta.

Victoria, Agatha Olivia. (2020). "Tingkat Pengangguran Lulusan SMK Paling Tinggi".

https://katadata.co.id/agustiyanti/finansial/5eb 12802ca798/tingkat-pengangguranlulusan-smk-paling-tinggi. (diambil 5 Mei 2020: 15:42) 